Article

\title{
Exploring the Determinants of Residential Satisfaction in Historic Urban Quarters: Towards Sustainability of the Walled City Famagusta, North Cyprus
}

\author{
Tina Davoodi * and Uğur Ulaş Dağlı \\ Faculty of Architecture, Eastern Mediterranean University North Cyprus, \\ 99450 Famagusta, via Mersin, 10, Turkey; ugurulasdagli@gmail.com \\ * Correspondence: tinadavoodi8234@yahoo.com
}

Received: 4 October 2019; Accepted: 4 November 2019; Published: 7 November 2019

check for updates

\begin{abstract}
In recent times, despite the importance of historic urban quarters in the sustenance of ancient cultural heritage, planned modernization of urban areas usually neglects these culturally sensitive areas. Resulting in relocations and perceived dissatisfaction of its residents, this reported negligence is partly the result of a dearth of research exploring the multi-dimensional evaluation framework for assessing the long-term environmental, economic, social, and cultural aspects of residential satisfaction in historic urban quarters. Hence, the aspirations, needs, demands, and desires of the residents of historic urban quarters are not readily known to policy makers; neither is these needs, desires and expectations are well established in the residential satisfaction literature. The essence of residential satisfaction research is not merely to report the current living situation in a given residential environment, but also to pinpoint which facets the municipal governments must enhance to improve homeownership and rental rates, amongst others. Most of the studies on residential satisfaction merely focused on the social sustainability dimension, therefore, not acknowledging the salient roles, environmental, and economic concerns play in boosting the satisfaction levels of residents of historic urban quarters. Thus, this study aims to fill this gap between theory and application of the sustainability concept in addressing practical problems of relocations and perceived dissatisfaction amid residents of urban culturally sensitive areas. It fills this gap by assessing the perceptions of residents and non-residents on the importance of the determinants of residential satisfaction in a historic urban quarter. Regarding this, a comprehensive list of 32 potential sustainability performance factors (SPF) was determined through an extensive review of related literature, based on which a questionnaire administered to 245 households residing in the historic urban quarters of the Walled City, Famagusta, North Cyprus. Also, 167 households residing outside of the quarters, to assess their perception of the criticality of the identified factors, as well as examine the agreement levels in the opinions of the two participant groups. Using principal component analysis (PCA), the 32 different factors were narrowed down to eight. The study findings show that "Cost of housing" and "Suitable Management rules" are the most critical factors with relatively high overall scoring. Findings reveal that residents' perceptions differ significantly based on participants' ethnicity, while there is no significant difference based on the profile of residents/social class. This study argues that clearly understanding the criticality of the factors impacting satisfaction in housing and the residential environment is crucial for planning sustainable regeneration and revitalization programs in any HUQ. The findings of this study would be useful to housing policy decision-makers, urban planners, and municipalities to understand better the residents' needs that could aid the sustenance of historic urban quarters. The authors suggest the adoption of the framework developed by this study as an analytical, research, and assessment tool in future housing satisfaction studies in different contexts.
\end{abstract}


Keywords: residential satisfaction; sustainability; historic urban quarters; residential desires; household perception; quantitative analysis; Walled City; Famagusta

\section{Introduction}

Historic urban quarters (HUQ) are projections of various historical elements such as residential buildings and environments, which are symbolically linked with other parts of the city [1,2]. Urban quarters are considered historical by their ancient and traditional features like local branding characteristics, urban fabric, and street patterns [3]. Places occupied by these quarters are unique in terms of a host of the country's heritage (cultural or historical). They are evidenced by their traditional character and architectural value [4]. Despite the importance of HUQ in the sustenance of ancient cultural heritage, planned modernization of urban areas usually neglects these culturally sensitive areas. For instance, [5] opined that in Turkey, households' satisfaction with their neighborhoods has not gained the attention of policymakers. The same scenario is experienced in the Turkish Republic of North Cyprus. This negligence has led to continued reported cases of relocations and perceived dissatisfaction amongst its residents.

These reported cases of negligence are partly the result of a lack of research exploring the multi-dimensional evaluation framework for assessing the long term environmental, economic, social, and cultural aspects of HUQ. Hence, the aspirations, needs, demands, expectations, and desires of the residents of HUQ are not readily known to policymakers; neither is these needs, desires and expectations are established in housing satisfaction literature. Most of the studies on this subject merely focused on the social sustainability dimension, therefore, marginally acknowledging the salient roles, environmental, and economic concerns play in boosting the satisfaction levels of residents of HUQ.

Residential satisfaction is a complex concept which has been studied by several researchers of diverse orientation and discipline., using different theoretical and conceptual approach. However, many studies have examined the determinants of residential satisfaction in various contexts, for instance, at neighborhood and country levels [6-8], public housing [9-11], private housing [12]. However, to the best of our knowledge, no study has explored the residential satisfaction in HUQ particulary from the prism of sustainability. No study has explored the residential satisfaction in HUQ. The study by [3] only proposed a model for measuring the sustainability levels in the HUQ of the Walled City, Famagusta. The authors combined the concepts of sustainability and revitalization to measure sustainability levels, but in no way did they relate the study to residential satisfaction amongst residents of the Walled City. More so, policies which incorporate the social, physical, and economic aspects of sustainability, to revitalize the HUQ have been proposed and implemented. International documents and conventions establish the foundation for these local policies. Nevertheless, an extended review of the literature clearly shows that the outcomes of these policy implementations have not always succeeded due to little or no linkage to residential satisfaction or user participation.

Therefore, this research explores the concept of residential satisfaction within the context of HUQ. This paper then examines the criticality of residential satisfaction determinants from the perceptions of residents of HUQ within the ambit of the sustainability concept. This exploratory research was designed as a case study in the Walled City of Famagusta, North Cyprus, which is the oldest gated community in Famagusta. Several studies have remarked that the HUQ of the Walled City, Famagusta, is characterized by poor structural conditions, dilapidating buildings, poor living environment, as well as outdated sanitary and infrastructure systems [1,13]. According to [3], this historic area has suffered significant physical and social decay, resulting in declining economic and tourist activities.

Consequently, the living standards in the quarters may not satisfy the contemporary needs of residents. This dissatisfaction has led to reported low rates of homeownership, poor property rentals and eventual relocation of residents [14]. A study by [15] pointed out that the sustainability of historic 
urban areas in fast-developing countries is confronted with the serious dilemmas of loss of indigenous people and identity, who are currently embracing social and economic transitions.

This study explores the perceptions of residents living in physically different neighborhoods (those residents in the Walled City and others residing in adjacent districts) in order to demonstrate the diversities when defining residential satisfaction within the same district (old and new). In so doing, it reveals the differences and similarities in perceptions of residents of HUQ, and apartment buildings erected during improvement plans and urban transformation programs.

This research aims to fill this literature gap by assessing the subjective perceptions of residents concerning this matter, from economic, environmental, cultural and social perspectives. The key objective of this study is to establish, validate and analyze a comprehensive list of factors through which satisfaction levels of residents in HUQ can be assessed holistically and sustainably. Sub-objectives are (1) To determine the importance of the identified factors using residents' subjective perception. (2) To establish if the opinions on the factor's importance differ depending on the respondent's ethnicity (e.g., local or foreign)? (3) To determine if participants residing in adjacent districts have differing opinions on the factor's importance? (4) To determine if the opinions on the factor's importance differ depending on the profile of residence (e.g., homeowner or renter)? (5) To develop an analytical, research and assessment framework for future housing satisfaction studies in different contexts (urban or rural, country or region), period, places and profile of residents.

Based on the main research question, i.e., What social, environmental, economic, and cultural factors shape and increase housing satisfaction amongst residents of HUQ in the study area?, the following four sub-questions emerge: (1) To what extent is each factor important based on residents and non-resident's perception? (2) Do the perceptions of the factor's importance differ depending on the resident's ethnicity (e.g., local or foreign)? (3) Do the perceptions of the factor's importance differ depending on the respondent's profile of residents/social class? This study is guided by the postulation that:

Null Hypothesis 1 (H1): Residents' perceptions on the determinants of residential satisfaction in HUQ do not significantly differ based on ethnicity.

Null Hypothesis 2 (H2): Residents' perceptions on the determinants of residential satisfaction in HUQ do not significantly differ based on profile of residence/social class.

The answers to these questions and sub-questions and the analysis of the hypothetical statement will present sound evidence on how to enhance sustainability of HUQ in a developing country context. Also, it would help suggest sustainable solutions which would aid housing authorities, government, and stakeholders in these culturally sensitive areas. This paper contributes to the existing literature in two ways. Firstly, it enriches the housing literature theoretically. It extends the meaning and dimensions of residential satisfaction by exposing housing satisfaction perceptions of residents in HUQ. Secondly, the study practically contributes to the existing literature. Identifying factors affecting residential satisfaction in HUQ takes a central role in improving the quality of residential, environmental, and housing layouts, as well as the quality of life. Therefore, the findings of this research will aid city planners, housing and municipality authorities in better management of residential settings regarding the needs and expectations of residents of HUQ.

Furthermore, the assessment of residential satisfaction in HUQ is of great importance to the municipal government of Famagusta. In the sense that the local authorities will not only be aware of how satisfied the residents of HUQ feel about their present living situation and if the identified factors have correlations with residential satisfaction. Also, the assessment would inform the authorities of the critical factors that would most strongly predict the residential satisfaction in HUQ. Consequently, the municipal governments would understand how to improve the habitability and sustainability of HUQ instead of solely relying on experts, professionals' previous experiences in housing. In addition, the residents would be sure that what the municipal government would deal with is those critical factors they have concern for. Therefore, a sustainable relationship would be established between the residents and municipal government for enhanced habitability and sustainability of HUQ. 
The rest of this study is structured accordingly; Section 2 reviews an extant body of literature relating to residential satisfaction and sustainability. Section 3 explains the study methodology and the research protocol. Section 4 deals with study results following the research questions and objectives. Section 5 discusses the research findings. Section 6 deals with research contributions and limitations, research agenda for future studies. Section 7 presents the conclusion as illustrated in Figure 1.

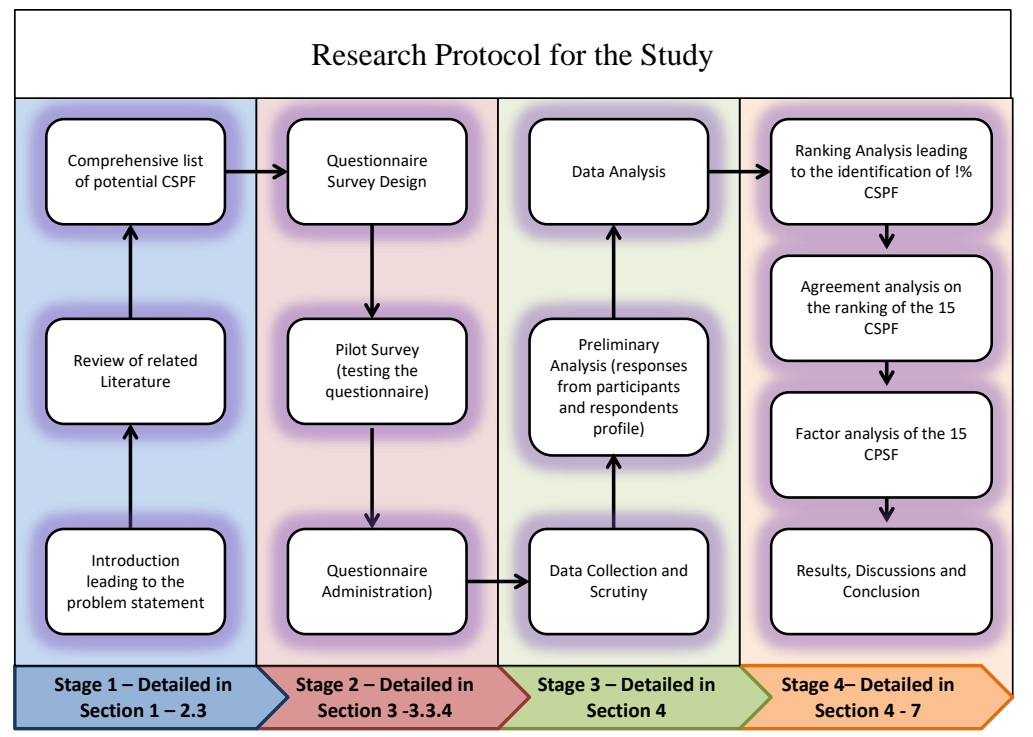

Figure 1. Research Design for the study. Note: Critical sustainability performance factors (CSPF).

The terms housing, dwelling and residential in this paper are used interchangeably. This intermittent use of the terms was observed in prior studies on housing and residential satisfaction. They refer to the same meaning.

\section{Literature Review}

\subsection{The Concept of Residential Satisfaction}

The residential satisfaction construct is a nebulous in nature [16], having been a topical subject that is fiercely studied by scholars and researchers of different discipline such as sociology, planning, urban, geography, architect, psychology, amongst others [17-19]. [20] reported that "the concept of residential satisfaction is often employed to evaluate residents' perceptions of and feelings for their housing units and the environment." Residential satisfaction is generally understood as the feeling of contentment when individuals' needs, concerns, or aspirations in a residential environment are met. Residential satisfaction should assess the peoples' housing conditions and environmental concerns regarding the needs, expectations, and desires. [21] described residential satisfaction as the perception of the difference between residential expectation and reality of residents. According to [22], residential satisfaction is a complex construct that involves complex terms, different processes, and theories such as housing, environment and satisfaction terms, cognitive, affective and behavioural processes, housing need, and deficit theories, as well as psychological construct theories.

In the behavioural sense, residential satisfaction refers to the dependent attitude towards the residential environment. [23] suggested that three components of an attitude are emotional, informational, and behavioural. Many researchers prefer the emotional definition of residential satisfaction, while some prefer perception-based definitions [24]. The emotional dimension entails the reflection of sentiments of happiness and satisfaction which then creates these feelings $[25,26]$. In the case of the informational definition of residential satisfaction, it constitutes the correspondence between the current conditions, standards, and quality, residents' desire and demand [27,28]. Studies suggested that residential satisfaction increases with the decrease in the gap between demand and need $[17,29,30]$. 
Several factors influence residential satisfaction, e.g., resident's social background, circumstances, habits, expectations, experiences, desires and needs [31,32], the housing age [33], residential neighbourhood and community characteristics [34], community participation [35], amongst many others. These factors do not have the same degree of influence in different cultures or countries. For instance, [36] demonstrated that residential satisfaction in China is different from what is obtainable in Western countries. These dissimilarities are as a result of different socio-cultural, psychological, and physical environmental and other factors that form the residential built environment.

Furthermore, [37] opined that residential satisfaction construct as an approach to advise on need-based improvements of residential settings is flawed. The author proposed the concept of 'marginal residential improvement priority' as an alternative to residential satisfaction evaluation studies. 'Marginal improvement priority,' is a scenario whereby the researcher selects a set of factors and enjoins the residents to rank them based on what they want improved relying on their preferences. Hence, variations in the implementation of the residential satisfaction concept are possible and better even. This technique, however, has received criticism from some scholars $[16,38]$.

These criticisms point to the complex nature and subjective manner of the concept of residential satisfaction. Nevertheless, many studies continue to apply the 'Marginal improvement priority' approach to the concept of residential satisfaction in a different residential environment to explore what constitutes and influences residential satisfaction. It is also applied to provide insights that guide and inform policy formulations that can boost residents' satisfaction level. These benefits of residential satisfaction studies could be valuable to the HUQ if a similar approach is applied. The municipality and housing management authorities could use the findings of this research to improve housing governance and policies in HUQ.

To the best of our knowledge, residential satisfaction studies on HUQ are non-existent. This gap in knowledge has brought about the lack of understanding of the uniqueness of residential satisfaction in a HUQ. Hence, exploratory research of residential satisfaction in this context and scope of HUQ is duly necessary.

\subsection{Residential Satisfaction in HUQ}

HUQ have special relevance in a country's cultural and historical heritage, since they are coherent entities, which are defined by their architectural value and traditional character. According to [14], HUQ consist of physical structures, intangible and tangible heritage of olden days while also showcasing the peoples' culture and their way of living. HUQ can be found in several countries; they reflect the accomplishments of a civilisation over the centuries. [39] opined that these quarters are the gathering of historical or cultural buildings, which present features and style of a certain historical era. Many highlight efforts of indigenous cultures, some the effect imported or colonial activity. These forces of influence mingle creatively to establish unique forms and patterns [2].

In continuation, it is possible to identify in HUQ houses in poor conditions, insufficient parking spaces, non-contemporary sanitary conditions, buildings used for less suitable purposes, narrow roads, changes in the pattern of ownership; diminishing attractiveness, changing social composition, and rising rates of vacant dwellings. All these concerns are symptoms of decay and deterioration.

Residential satisfaction researchers often overlook some context and/or factors that impact resident's satisfaction. For example, there is no study on residential satisfaction in HUQ. Several scholars noted that residential settings in a HUQ differ significantly from other forms of housing $[2,3,5]$. The architectural value of the residential settings, the tourism scenarios accompanied by its economic potentials, as well as the strict management rules guiding renovations and construction of new houses, may have a strong influence on residents' psychological construct in terms of residential satisfaction. In private or public urban housing, residents enjoy the liberty to transform or modify their houses and environment according to their financial strength. Unlike in HUQ, these enjoyment rights are not guaranteed, and on many occasions, is denied. 
Therefore, residential satisfaction in HUQ may differ from those of other context like urban private and public housing.

\subsection{Establishing Potential Critical Sustainability Performance Factors for Residential Satisfaction in HUQ}

It is important to establish potential critical sustainability performance factors (CSPF) for residential satisfaction in HUQ, within the ambit of sustainability. Because [40] argues that the decaying character of the walled city is a problem in Famagusta, as the measures undertaken for its conversion and revitalization have not led to the attainment of a satisfactory state in terms of cultural or economic sustainability. A recent study by [14] developed a regeneration framework for professionals, different governmental agencies, institutions, and experts, the components that were reviewed and analysed in their framework are the results of municipality authorities that are presently confronted by planning problems. The authors attempt to reverse the decline of HUQ by solely channelling attention onto how governmental agencies, institutions, and experts can improve the physical structure and how the economy of HUQ creates a void in the social life and construct of those areas. Hence, it has become imperative that residents' input towards the sustainable revitalisation of HUQ is long overdue.

Therefore, to establish the relevance of the various CSPF that affect residential satisfaction in HUQ, an in-depth literature review on CSPF was performed. Residential satisfaction literature suggests that residential satisfaction means more than physical satisfaction [6,40]. It consists of satisfaction derived from aesthetic, quality/adequacy and environmental settings, [41,42], the monetary value of dwellings [43,44], community satisfaction [6,45], satisfaction derived from urban services in the housing environment $[16,46,47]$. Although these dimensions shape the overall housing satisfaction, its definition is a subjective and context-dependent phenomenon [28,48]. It depends on the current conditions, needs and characteristics of residents. With this understanding, the research motive of this study is to reveal the context of residential satisfaction of a specific setting (the residents of HUQ).

\subsubsection{Social Dimension of Residential Satisfaction:}

Several studies have been conducted on the social dimension of residential satisfaction, which includes aspects of community satisfaction. For instance, it was noted that housing satisfaction could be strongly influenced by social and environmental living conditions [6]. Many of these studies highlight the various drivers of social and environmental living conditions in modern/urban and traditional/rural areas. It was established that housing satisfaction perceptions differ from modern/urban and traditional/rural areas [49]. Several studies have demonstrated that social interaction within the neighbourhood not only improves the overall housing satisfaction but is also influenced the satisfaction of neighbourhood social life [12,50,51]. For instance, social homogeneity [46], improved community spaces [52], community support [53], existence of relatives in the neighborhood [54], good social network [45] such as baby-sitting, social support and sharing food, materials and experience [55], membership to a social class and local social attachments [56] increase residential satisfaction levels.

\subsubsection{Economic Dimension of Residential Satisfaction:}

Several studies revealed that homeownership is the main determinant that defines the economic dimension of housing satisfaction [44,57]. A drop in the cost of housing brings about dissatisfaction amongst homeowners [43]. In addition, the physical upkeep of neighbouring homes [43] and payments for homeownership [58] contribute to the economic dimension of residential satisfaction. The economic dimension consists not just of the cost or payment terms for a dwelling but also the resident's level of income, which is generally termed the affordability of a dwelling.

\subsubsection{Environmental Dimension of Residential Satisfaction:}

The environmental or physical dimension of residential satisfaction consists of building type, size, functionality, physical quality, aesthetic aspects, housing environment and location of housing layout. In addition, shared use of some amenities and areas outside the house could also count as a 
factor of satisfaction $[59,60]$. The type of building can impact the quality of the physical and social life of residents. For instance, studies have suggested that a building, which promotes privacy, could be assessed as an attribute that impacts satisfaction $[57,61]$. The factors related to the structural and internal quality of housing were introduced by [16]. [62] found that poor construction quality leads to frequent maintenance, which results in dissatisfaction. Therefore, home maintenance dissatisfaction leads to dissatisfaction with the use of a home [63].

Physical or environmental quality [41,46], odour [57], noise [64], security problems [51], safety problems [12,55], heavy traffic, uncontrolled growth [65], accident rate [51] are other factors that influence residential satisfaction in a neighborhood. Also, the function within a house such as washing, cooking, and sanitary facilities, and ventilation [66], varieties in room types (living and bedrooms), size and number of rooms [12,51], room locations [61], presences of a balcony [58], brightness and sunshine [58] are all attributes used to measure residential quality and housing satisfaction.

\subsubsection{Cultural Dimension of Residential Satisfaction:}

According to [24], a dwelling is not just a structure full of things; the culture influences its organisation and forms. Thus, it is deemed to reflect the relationship between environment, culture, and residential satisfaction. Culture is an all-inclusive notion, and its meaning could be derived from the collected studies which cover three major areas that influence residents' satisfaction and socio-cultural experiences of people in housing [67]. Culture in the housing development perspective simply means the process by which individuals adapt to their environment [68].

According to [69], the idea of cultural influences has not been established like that of social influences, and most often, it is listed under social influences as a result of its social dimension. A distinctive feature of cultural development is, nonetheless, the preservation of housing heritage. For instance, [70] pointed out that comparative studies in Eastern and Western countries, using a standard tool, should help to detect cultural differences in the dimensions affecting more general social-psychological responses such as neighborhood attachment and residential satisfaction. [68] observed that certain cognitive factors such as experience and socio-cultural background affect the level of human perception of their housing environment. Thus, the satisfaction derived by the inhabitants of a particular housing unit is a reflection of the degree to which they feel in conformity with their socio-cultural background [71]. [68] mentioned that the lack of socio-cultural considerations such as family values, the ethnicity of end-users, family size, religion among others, and poor utilisation of research findings are among such major constraints to housing satisfaction. Furthermore, the author stated that attitudes towards space, use, and organisation of space are all linked to cultural traditions, which are often best understood by the local people themselves.

With the understanding of the above discussions, a holistic set of CSPF affecting residential satisfaction in HUQ was identified (Table 1). Followed by questionnaire design, which was pilot surveyed and administered to residents of HUQ and those residing in adjacent districts. Before the questionnaire design, a pilot survey was performed on the potential list of CSPF affecting residential satisfaction in HUQ. The reason for the process was to test the comprehensiveness and the significance of the possible CSPF. One residential district in the HUQ was used in the pilot study comprising low and medium-income earners, who have lived in the Walled City for more than five years. The participants were asked to evaluate if the factors listed in the questionnaire contained a suitable number of performance factors and if other potential critical performance factors may be included or expunged from the list. One factor each was added to the economic, cultural and environmental dimensions. Consequently, a total of 3 factors was added to the comprehensive set of CSPF through the pilot survey as shown in Table 1. The completeness and relevance of the factors were finalised and confirmed after the pilot study. 
Table 1. Comprehensive set of CSPF affecting residential satisfaction in HUQ with selected references.

\begin{tabular}{|c|c|c|c|}
\hline Dimension & Sustainability Performance Factors & Code & Relevant Reference \\
\hline \multirow{6}{*}{ Economic } & Cost of housing & (ESPF01) & {$[50,72]$} \\
\hline & Job creation in the form of home-based enterprise & (ESPF02) & [63] \\
\hline & Tenure options & (ESPF03) & {$[50]$} \\
\hline & Suitability of housing acquisition process & (ESPF04) & (Pilot Survey) \\
\hline & Cost of living within the gated community & (ESPF05) & [73] \\
\hline & Adaptability of housing units for future needs & (ESPF06) & (Pilot Survey) \\
\hline \multirow{10}{*}{ Social } & Access to social infrastructure & (SSPF01) & {$[31,51]$} \\
\hline & Social networks capable of generating social capital & (SSPF02) & [53] \\
\hline & Provision of recreational/ sporting facilities & (SSPF03) & {$[74,75]$} \\
\hline & Security/safety concerns & (SSPF04) & {$[76,77]$} \\
\hline & Housing near to the places of work and worship & (SSPF05) & {$[51,63]$} \\
\hline & Suitable Management rules & (SSPF06) & {$[6,75]$} \\
\hline & Level of social mix in housing environment & (SSPF07) & {$[72]$} \\
\hline & Quality of internal spaces of housing units & (SSPF08) & {$[61,76]$} \\
\hline & Privacy in dwelling units & (SSPF09) & {$[57,61]$} \\
\hline & Housing contribution to the aesthetics of urban landscape and morphology & (SSPF10) & [78] \\
\hline \multirow{3}{*}{ Cultural } & Architectural design of housing in relation to cultural values & (CCPF01) & (Pilot Survey) \\
\hline & Suitability of housing to occupants natural way of life & (CCPF02) & (Pilot Survey) \\
\hline & $\begin{array}{c}\text { Reflection of the unique historical and cultural characteristics of the area in the } \\
\text { design and erection of new dwellings }\end{array}$ & $(\mathrm{CCPF} 03)$ & {$[56,79]$} \\
\hline \multirow{11}{*}{ Environmental } & Quality of dwelling Environment & (ETSPF01) & {$[61,76]$} \\
\hline & Neighbourhood Environmental Quality & (ETSPF02) & {$[20,31,80]$} \\
\hline & Housing Density/Building Type & (ETSPF03) & {$[57,68]$} \\
\hline & $\begin{array}{c}\text { Architectural solution to energy consumption issues (e.g., ventilation, lighting, } \\
\text { building morphology) }\end{array}$ & (ETSPF04) & {$[57,75]$} \\
\hline & Construction techniques and materials & (ETSPF05) & {$[16,50]$} \\
\hline & Landscaping Elements & (ETSPF06) & [63] \\
\hline & Reduced dependency on car within the gated community & (ETSPF07) & (Pilot Survey) \\
\hline & Storm water discharge system & (ETSPF08) & [81] \\
\hline & Waste management system & (ETSPF09) & [82] \\
\hline & Main sources of power and water supply & (ETSPF10) & {$[10,31]$} \\
\hline & Open Spaces and Green areas & (ETSPF11) & [63] \\
\hline
\end{tabular}

Note: Critical sustainability performance factors (CSPF), Historic urban quarters (HUQ). 


\section{Methodology}

\subsection{Case Study Area}

This article intends to explore dimensions of residential satisfaction from the perceptions of residents of HUQ. This exploratory research was designed as a case study in the Walled City of Famagusta, North Cyprus, which is one of the oldest gated communities in Famagusta. The city of Famagusta is the Turkish Republic of Northern Cyprus's second-largest city. The city is a historic core and also houses a harbour, it is an important tourism and trade centre, and served as a regional centre before the island's division as a result of the 1970s' conflict. Currently, Famagusta houses the largest and most well-equipped seaport, which serves the entire Turkish Republic of Northern Cyprus.

Cyprus, which is the third largest island in the Mediterranean Sea, is located $60 \mathrm{~km}$ south of Turkey's coast, $322 \mathrm{~km}$ from Greece, and $96 \mathrm{~km}$ west of the Syrian coast [83]. The historic residential district of the Walled City, which is used as a case study, is positioned on the eastern coast of the island in the northern part of Cyprus. It is located in Famagusta (the second biggest city of Northern Cyprus). Figure 2a-c shows the location of Famagusta, Cyprus, and the historic residential district of the Walled City, respectively. As shown by dash lines in Figure 2c, the Walled City is surrounded with fortifications; these fortifications consist of Venetian-era masonry walls continuously surrounding the settlement.

Currently, in the Walled City, the neighbourhood features can be described in five categories, namely, Old/historical, high density in 3-d framework, 1-2 storey houses (courtyard houses dominant), Partial mixed-use, Middle-to-high /low income [84]. According to [85] the Walled City is characterized by its unique organic urban character with narrow streets and low-rise dwellings, which developed through various historical periods. The Walled City of Famagusta experiences several aspects of negative social value [80]. It was associated with segregation, during the armed conflict of the 1970s. When the Greek Cypriots fled, and the remaining Turkish Cypriots sought refuge in the Walled City. Also, developments outside the Wall City are attracting its residents with economic means, to relocate to adjacent districts, leaving behind a poor and old population, mostly immigrants. Many residents have abandoned the Walled City for newly constructed suburban apartments and villas [85]. These relocations have led to a low sense of community or neighbourhood and have spurred studies to propose conservation and revitalisation measures [2,86], and framework for regeneration process [14] of the HUQ of the Walled City, Famagusta

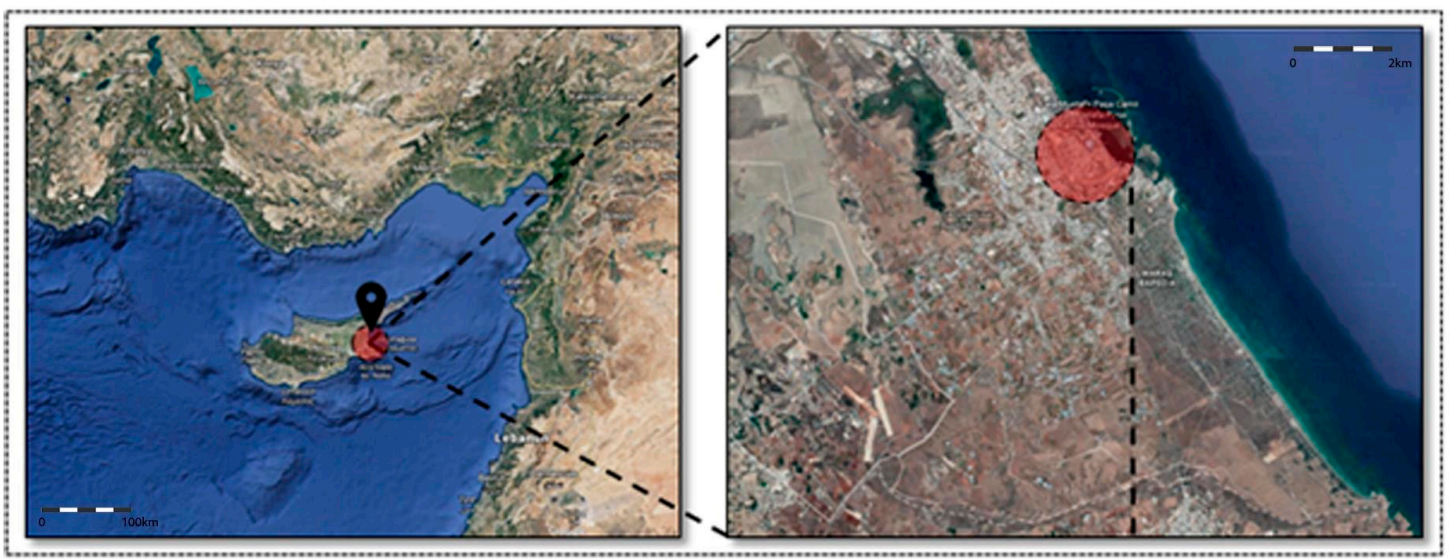

(a) Location of Cyprus

(b) Location of Famagusta

Figure 2. Cont. 


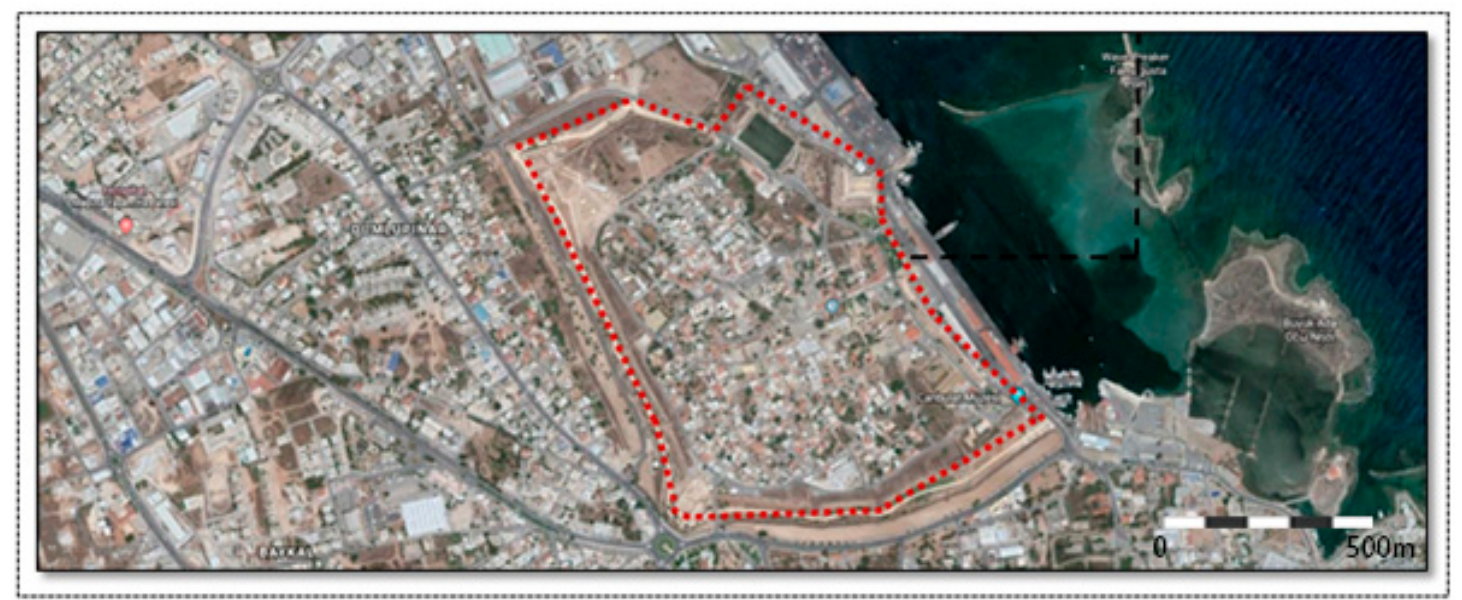

(c). Location of Walled City

Figure 2. Geographical location. Source: Extracted and modified from Google Earth (2018).

\section{Housing and Urban Conditions in North Cyprus}

North Cyprus is host to strong and rich civilisations in the Mediterranean region [40,80]; it is home to diverse housing forms, residential patterns, and architectural styles, each with its unique identity [87]. The first recorded example of the architecture dates back to the Neolithic Period, which influences and affect the cultural characteristics of the society [88]. It is perceived that the planning system in Northern Cyprus is creating a disorganised and unstable situation, resulting in disappointing feelings, low quality residential physical and social environments. The poor contributions of regulatory bodies and/or national policies towards contemporary concepts of urban growth and planning such as sustainable development, ecological concerns, a compact cities approach, and many others, as well as the insufficient development control over rapid urbanisation, in urban and rural settlements. These inadequacies lead to the two main negative inputs in the development of urban environments in general, and in particular, the residential environments [87].

Having examined the housing situation in Northern Cyprus from historic to the contemporary era, the problems of housing and residential developments could be defined into two separate but interrelated perspectives: the internal problems in the housing sector, and its impact on the social, physical, cultural and economic environments [87]. Therefore, these challanges implies that housing development trends and planning implementations in Northern Cyprus are tilting towards unsustainable land-use practices and unsustainable design solutions.

\subsection{Data Collection:}

This research consists of a comprehensive literature review to enable the assemblage of a holistic set of CSPF influencing residential satisfaction in HUQ. Altogether, 32 potential CSPF were identified (Table 1), with the first objectives to determine the criticalities of these CSPF from the residents' point of view, followed by finding out the disparities (if any) between respondents based on ethnicity (local or foreign) and profile of residence (social class) on the ranking of the established CSPF and lastly, classifying the established CSPF into underlying categories. The A Section of the questionnaire demanded the respondents' background data. It requested background questions in order to form filters, which enable comparisons of different group's opinions on the importance of factors, such as gender, age, income. It is important to determine the reliability of the responses before further analysis is conducted on subsequent data. In Section B, participants were requested to assess the criticality of the 32 CSPF via a 5-point Likert Scale of $1-5$ as follows: $5=$ Very important; $4=$ important; $3=$ slightly important; 2 = less important and 1 = least important; which represent the importance of residential satisfaction determinants from the residents' perspective. The adoption of this scale was due to its 
relative brevity. Thoughtfully, at the end of the 32nd CSPF, spaces were provided for participants to rate and list the criticality of other CSPF as may be identified by them (see Supplementary Materials). This exercise allowed the inclusion of an additional 4 CSPF in the comprehensive list.

Sampling

The convenience sampling technique was used for the collection of primary data. In convenience sampling, the survey administration is targeted at willing, available and accessible respondents [89]. This technique is suitable where adequate information on population size is lacking. Therefore, findings drawn may not be generalizable; however, using more respondents, the findings can be representative [89]. The case study utilises data gathered from two questionnaire surveys carried out between March and September 2019, focusing on the residents of HUQ and those living in adjacent districts.

\subsection{Analytical Tools and Techniques}

This study employed both descriptive and inferential analysis techniques. The choice of the analytical background (parametric or non-parametric technique) was ascertained by a normality test using the one-sample Kolmogorov-Smirnov approach for large sample data. Confirmation of non-normality of the field data $(\mathrm{K}-\mathrm{S}$ stat. $=0.643 ; p$-value $=0.2902)$ informed the use of non-parametric statistical tools. Particularly, the descriptive-analytical tools employed were Relative Importance Index (RII), while inferential statistics used include: Mann-Whitney U test and exploratory factor analysis mechanism. These tools are briefly discussed below:

i. $\quad$ Relative Importance Index (RII): This is a descriptive statistical technique for extracting key variables (or factors) from the complexity of multivariate data. It is suitable when the researcher's interest is to extract or determine major important factors from a multitude or population. The Relative Importance Index (RII) is usually expressed in percentages. Mathematically, the RII is obtained as follows:

$$
R I I=\frac{\sum_{i=1}^{n} W_{i} n_{i}}{A \times N} \times 100
$$

where $W_{i}=$ weight of each ith total response given by the respondents. In this case, it ranges from 1 to 5

$n_{i}=$ total number responses in each response box

$A=$ the highest weight in the scale, " 5 "

$N=$ the total number of respondents [90]

ii. Mann-Whitney U-test: The Mann-Whitney U-test is a non-parametric statistical equivalence of an independent samples t-test. However, the Mann-Whitney $U$ test is used to test whether a difference in the means of two independent samples is statistically significant (in this case, local, foreigner). It is computed as:

$\mathrm{U}=N_{1} N_{2}+\frac{N_{1}\left(N_{1}+1\right)}{2}-\mathrm{R}_{1}$

where $N_{1}$ and $N_{2}=$ sample size

$\mathrm{R}_{1}$ and $\mathrm{R}_{2}=$ sum of the ranks for each of the samples.

iii. Factor Analysis: This is an advanced statistics used when the researcher's interest is to condense and simplify the multivariate data, thereby pointing out important and interesting relationships among the observed data. Particularly, the Exploratory Factor Analysis (EFA) is appropriate when the research interest is to identify factors based on the available data to maximise the amount of variance explained. This study employed the exploratory factor analysis estimation 
technique to condense and extract the critical determinants of residential satisfaction in HUQ of Walled City Famagusta, North Cyprus.

The multiple correlation analysis technique was employed to establish relationships among the variables. The correlation coefficients (by the product-moment method) between the pairs of $k$ variables are determined and arranged, as shown in Table 2, in the form of a correlation matrix, $R$ :

Table 2. Correlation Matrix Table.

\begin{tabular}{|c|c|c|c|c|c|}
\hline & $X_{1}$ & $X_{2}$ & $X_{3}$ & $\ldots$ & $X_{k}$ \\
\hline$X_{1}$ & $r_{11}$ & $r_{12}$ & $r_{13}$ & $\ldots$ & $r_{1 k}$ \\
\hline$X_{2}$ & $r_{21}$ & $r_{22}$ & $r_{23}$ & $\ldots$ & $r_{2 k}$ \\
\hline Variables $X_{3}$ & $r_{31}$ & $r_{32}$ & $r_{33}$ & $\ldots$ & $r_{3 k}$ \\
\hline . & . & . & . & . & . \\
\hline . & & . & . & . & . \\
\hline . & . & . & . & . & . \\
\hline$X_{k}$ & $r_{k 1}$ & $r_{k 2}$ & $r_{k 3}$ & $\ldots$ & $r_{k k}$ \\
\hline
\end{tabular}

where $r_{i j}$ is computed as:

$$
r=\frac{\operatorname{Cov}(X, Y)}{\sqrt{(\operatorname{Var}(X))(\operatorname{Var}(Y))}}=\frac{\sum_{i=1}^{n}[(X-\bar{X})(Y-\bar{Y})]}{\sqrt{\left[\sum_{i=1}^{n}(X-\bar{X})^{2}\right]\left[\sum_{i=1}^{n}(Y-\bar{Y})^{2}\right]}}
$$

where

$r$ is the correlation coefficient,

$\operatorname{Cov}(X, Y)=\sum_{i=1}^{n}[(X-\bar{X})(Y-\bar{Y})]$ is the covariance of $X$ and $Y$ series,

$\operatorname{Var}(X)=\sum_{i=1}^{n}(X-\bar{X})^{2}$ is the variance of $X$ series,

$\operatorname{Var}(Y)=\sum_{i=1}^{n}(Y-\bar{Y})^{2}$ is the variance of $Y$ series

$n=$ number of observations,

$\bar{X}$ and $\bar{Y}$ and mean values of series of $X$ and $Y$ values,

$X$ and $Y$ are variables of interest.

To explain the contribution performance of the extracted sustainability factors in the study area, the study employed the component scores, which are the individual contribution of the original variables for each sustainability factor to the variance explained by each component. It is calculated by the formula

$$
C S_{i k}=\sum_{j=1}^{n} D_{i j} L_{j k}
$$

where

$C S_{i k}$ is the score of ith observation in kth component,

$D_{i j}$ is the standardized value for $j$ th factor in ith observation,

$L_{j k}$ is the loading of factor $\mathrm{j}$ on component $\mathrm{K}$,

Summation is over all $\mathrm{N}$ variables.

However, the Principal Component Analysis (PCA) was used to remove severe autocorrelation found in the data to produce orthogonal results that are stable and reliable and which will serve as a framework for residential satisfaction in HUQ of Walled City Famagusta, North Cyprus. The statistical analysis was carried out using the SPSS (IBM Corp (2017). IBM SPSS Statistics for Windows, Version 25.0. Armonk, NY: IBM Corp.) windows program version 25.0. The level of significance is set at 0.05 . 


\section{Results and Interpretations}

\subsection{General Ranking of the Sustainability Factors for Increased Residential Satisfaction}

To determine the importance of the identified factors using residents' subjective perception, the Relative Importance Index (RII) analytical technique was employed. Table 3 contains a comprehensive list of the thirty-two (32) different sustainability performance factors for increased residential satisfaction amongst residents of HUQ and those living in adjacent districts. The essence is to identify the importance of these factors and extract the critical ones for further analysis.

Table 3. Ranking of the Sustainability Factors based on the Respondents' Groups.

\begin{tabular}{|c|c|c|c|c|c|c|c|c|}
\hline \multirow{3}{*}{ Code } & \multicolumn{2}{|c|}{ Profile } & \multicolumn{2}{|c|}{ Region } & \multicolumn{2}{|c|}{ Ethnicity } & \multirow{3}{*}{ RII (\%) } & \multirow{3}{*}{ Decision } \\
\hline & $\begin{array}{l}\text { Home } \\
\text { Owner }\end{array}$ & Renter & $\begin{array}{c}\text { HUQ } \\
\text { Dwellers }\end{array}$ & $\begin{array}{c}\text { Those Living } \\
\text { Outside }\end{array}$ & $\begin{array}{l}\text { Indigene } \\
(N=284)\end{array}$ & $\begin{array}{c}\text { Foreigners } \\
(N=164)\end{array}$ & & \\
\hline & $\begin{array}{c}\text { RII } \\
\text { (Rank) }\end{array}$ & $\begin{array}{c}\text { RII } \\
\text { (Rank) }\end{array}$ & $\begin{array}{c}\text { RII } \\
\text { (Rank) }\end{array}$ & RII (Rank) & $\begin{array}{c}\text { RII } \\
\text { (Rank) }\end{array}$ & $\begin{array}{c}\text { RII } \\
\text { (Rank) }\end{array}$ & & \\
\hline \multicolumn{9}{|c|}{ Economic Sustainability Performance Factors (ESPF) } \\
\hline ESPF01 & 89.33 & 88.61 & 79.34 & 98.6 & 88.24 & 89.70 & 88.97 & Extract \\
\hline ESPF02 & 49.87 & 55.57 & 44.10 & 61.34 & 50.76 & 54.68 & 52.72 & Ignore \\
\hline ESPF03 & 75.69 & 76.81 & 68.72 & 83.78 & 77.24 & 75.26 & 76.25 & Extract \\
\hline ESPF04 & 56.12 & 52.54 & 55.12 & 53.54 & 53.12 & 55.54 & 54.33 & Ignore \\
\hline ESPF05 & 88.62 & 88.26 & 89.23 & 87.65 & 89.01 & 87.87 & 88.44 & Extract \\
\hline ESPF06 & 50.22 & 48.62 & 50.76 & 48.08 & 48.22 & 50.62 & 49.42 & Ignore \\
\hline \multicolumn{9}{|c|}{ Social Sustainability Performance Factors (SSPF) } \\
\hline SSPF01 & 86.80 & 88.74 & 89.22 & 86.32 & 78.14 & 97.40 & 87.77 & Extract \\
\hline SSPF02 & 45.88 & 48.68 & 43.65 & 50.91 & 39.14 & 55.42 & 47.28 & Ignore \\
\hline SSPF03 & 52.15 & 49.63 & 52.02 & 49.76 & 27.45 & 74.33 & 50.89 & Ignore \\
\hline SSPF04 & 89.11 & 85.35 & 88.90 & 85.56 & 78.44 & 96.02 & 87.23 & Extract \\
\hline SSPF05 & 52.12 & 50.02 & 52.44 & 49.7 & 55.03 & 47.11 & 51.07 & Ignore \\
\hline SSPF06 & 88.01 & 84.93 & 86.77 & 86.17 & 80.06 & 92.88 & 86.47 & Extract \\
\hline SSPF07 & 83.74 & 88.14 & 88.25 & 83.63 & 76.43 & 95.45 & 85.94 & Extract \\
\hline SSPF08 & 62.57 & 67.79 & 69.32 & 61.04 & 62.00 & 68.36 & 65.18 & Extract \\
\hline SSPF09 & 49.87 & 49.69 & 48.97 & 50.59 & 38.24 & 61.32 & 49.78 & Ignore \\
\hline SSPF10 & 48.25 & 47.29 & 50.03 & 45.51 & 53.92 & 41.62 & 47.77 & Ignore \\
\hline \multicolumn{9}{|c|}{ Cultural Sustainability Performance Factors (CSPF) } \\
\hline CCPF01 & 80.96 & 81.18 & 79.88 & 82.26 & 78.59 & 83.55 & 81.07 & Extract \\
\hline CCPF02 & 61.00 & 60.16 & 62.16 & 59.00 & 53.98 & 67.18 & 60.58 & Extract \\
\hline CCPF03 & 79.38 & 80.62 & 81.22 & 78.78 & 61.77 & 98.23 & 80.00 & Extract \\
\hline \multicolumn{9}{|c|}{ Environmental/Technological Sustainability Performance Factors (ETSPF) } \\
\hline ETSPF01 & 82.77 & 83.21 & 79.67 & 86.31 & 70.58 & 95.40 & 82.99 & Extract \\
\hline ETSPF02 & 78.63 & 81.11 & 80.21 & 79.53 & 81.74 & 78.00 & 79.87 & Extract \\
\hline ETSPF03 & 51.01 & 48.99 & 44.56 & 55.44 & 60.22 & 39.78 & 50.00 & Ignore \\
\hline ETSPF04 & 43.06 & 44.18 & 48.37 & 38.87 & 40.71 & 46.53 & 43.62 & Ignore \\
\hline ETSPF05 & 44.00 & 40.74 & 40.77 & 43.97 & 38.85 & 45.89 & 42.37 & Ignore \\
\hline ETSPF06 & 44.89 & 45.47 & 46.34 & 44.02 & 47.92 & 42.44 & 45.18 & Ignore \\
\hline ETSPF07 & 85.34 & 84.22 & 86.11 & 83.45 & 83.87 & 85.69 & 84.78 & Extract \\
\hline ETSPF08 & 47.11 & 45.89 & 47.22 & 45.78 & 56.11 & 36.89 & 46.50 & Ignore \\
\hline ETSPF09 & 48.95 & 49.35 & 48.57 & 49.73 & 36.29 & 62.01 & 49.15 & Ignore \\
\hline ETSPF10 & 50.22 & 46.48 & 49.03 & 47.67 & 45.87 & 50.83 & 48.35 & Ignore \\
\hline ETSPF11 & 73.90 & 72.26 & 71.54 & 74.62 & 79.33 & 66.83 & 73.08 & Extract \\
\hline
\end{tabular}




\subsection{Ranking Analysis Leading to the Identification of 15 CPSF}

Quantitative evidence in Table 3 above shows that though there are variations in opinions of the respondents within the groups, there is equally some level of agreement in the respondents' opinions between the groups $\left(\mathrm{F}^{*}=3.014 ; p=0.2912\right)$. Based on Fisher's statistics, the top fifteen (15) factors were extracted on a benchmark score of $60 \%$ for acceptance and rejection otherwise. The pairwise comparison within the groups was performed using the non-parametric Mann-Whitney U test (for comparing two independent sample groups, see [91]. The essence was to strongly establish if the respondents' perception of the factor's importance is significantly different based on the respondents' profile: homeowner and renter; HUQ dwellers and those living outside; and ethnicity: locals and foreigners. The result is shown in Tables $4-6$ below:

Table 4. Comparison within the Respondents' Profile Groups: Home owner or Renter.

\begin{tabular}{cccc}
\hline Rank & Code & $\begin{array}{c}\text { Mann-Whitney U Statistic and Associated } \\
\text { Probability Values }\end{array}$ & $\begin{array}{c}\text { Ho: No Significant } \\
\text { Difference }\end{array}$ \\
\hline 1 & ESPF01 & Mann-Whitney U statistic $=0.773, p$-value $=0.1453$ & $\begin{array}{c}\text { Insignificant } \\
\text { Mann-Whitney U statistic }=0.381, p \text {-value }=0.4021\end{array}$ \\
2 & SSPF06 & Insignificant \\
3 & SSPF01 & Mann-Whitney U statistic $=-0.895, p$-value $=0.3710$ & Insignificant \\
4 & SSPF04 & Mann-Whitney U statistic $=0.225, p$-value $=0.6412$ & Insignificant \\
5 & ESPF05 & Mann-Whitney U statistic $=0.373, p$-value $=0.4790$ & Insignificant \\
6 & SSPF07 & Mann-Whitney U statistic $=-0.534, p$-value $=0.7231$ & Insignificant \\
7 & ETSPF07 & Mann-Whitney U statistic $=0.216, p$-value $=0.5316$ & Insignificant \\
8 & ETSPF01 & Mann-Whitney U statistic $=-0.173, p$-value $=0.8951$ & Insignificant \\
9 & CCPF01 & Mann-Whitney U statistic $=-0.326, p$-value $=0.5782$ & Insignificant \\
10 & CCPF03 & Mann-Whitney U statistic $=0.924, p$-value $=0.6552$ & Insignificant \\
11 & ETSPF02 & Mann-Whitney U statistic $=-0.829, p$-value $=0.7723$ & Insignificant \\
12 & ESPF03 & Mann-Whitney U statistic $=-0.284, p$-value $=0.2116$ & Insignificant \\
13 & ETSPF11 & Mann-Whitney U statistic $=0.554, p$-value $=0.2844$ & Insignificant \\
14 & SSPF08 & Mann-Whitney U statistic $=-0.338, p$-value $=0.2477$ & Insignificant \\
15 & CCPF02 & Mann-Whitney U statistic $=0.212, p$-value $=0.1051$ & Insignificant \\
\hline
\end{tabular}

\subsection{Agreement Analysis on the Ranking of the 15 CSPF}

The Mann-Whitney U test result, as shown in Table 4 above, indicates that the respondents' opinions on the factor's importance do not differ significantly based on their profile (homeowner or renter). This result authenticates the application of joint estimation and inferences.

Table 5. Comparison within the Respondents' Region: Urban dwellers or those living outside.

\begin{tabular}{|c|c|c|c|}
\hline Rank & Code & $\begin{array}{c}\text { Mann-Whitney U Statistic and Associated } \\
\text { Probability Values }\end{array}$ & $\begin{array}{l}\text { Ho: No Significant } \\
\text { Difference }\end{array}$ \\
\hline 1 & ESPF01 & Mann-Whitney U statistic $=-0.824, p$-value $=0.1105$ & Insignificant \\
\hline 2 & SSPF06 & Mann-Whitney U statistic $=0.629, p$-value $=0.3314$ & Insignificant \\
\hline 3 & SSPF01 & Mann-Whitney U statistic $=0.502, p$-value $=0.2117$ & Insignificant \\
\hline 4 & SSPF04 & Mann-Whitney U statistic $=0.533, p$-value $=0.2031$ & Insignificant \\
\hline 5 & ESPF05 & Mann-Whitney U statistic $=0.677, p$-value $=0.0916$ & Insignificant \\
\hline 6 & SSPF07 & Mann-Whitney U statistic $=0.609, p$-value $=0.2301$ & Insignificant \\
\hline 7 & ETSPF07 & Mann-Whitney U statistic $=0.772, p$-value $=0.1032$ & Insignificant \\
\hline 8 & ETSPF01 & Mann-Whitney U statistic $=-0.564, p$-value $=0.2314$ & Insignificant \\
\hline 9 & CCPF01 & Mann-Whitney U statistic $=-0.902, p$-value $=0.1226$ & Insignificant \\
\hline 10 & CCPF03 & Mann-Whitney U statistic $=0.887, p$-value $=0.4032$ & Insignificant \\
\hline 11 & ETSPF02 & Mann-Whitney U statistic $=0.744, p$-value $=0.1003$ & Insignificant \\
\hline 12 & ESPF03 & Mann-Whitney U statistic $=-0.683, p$-value $=0.0761$ & Insignificant \\
\hline 13 & ETSPF11 & Mann-Whitney U statistic $=-0.912, p$-value $=0.1208$ & Insignificant \\
\hline 14 & SSPF08 & Mann-Whitney U statistic $=0.639, p$-value $=0.0833$ & Insignificant \\
\hline 15 & CCPF02 & Mann-Whitney U statistic $=0.712, p$-value $=0.6102$ & Insignificant \\
\hline
\end{tabular}


The Mann-Whitney U test results in Table 5 above shows that the respondents' opinions on the factor's importance do not differ significantly based on their region (HUQ dwellers or living outside). This result implies that joint analysis can be carried out.

Table 6. Comparison within the Respondents' Ethnicity: Indigenes and Foreigners.

\begin{tabular}{cccc}
\hline Rank & Code & $\begin{array}{c}\text { Mann-Whitney U Statistic and Associated } \\
\text { Probability Values }\end{array}$ & $\begin{array}{c}\text { Ho: } \text { No Significant } \\
\text { Difference }\end{array}$ \\
\hline 1 & ESPF01 & Mann-Whitney U statistic $=-2.512, p$-value $=0.0001$ & $\begin{array}{c}\text { Significant } \\
\text { Mann-Whitney U statistic }=-2.611, p \text {-value }=0.0002\end{array}$ \\
3 & SSPF06 & Significant \\
4 & SSPF01 & Mann-Whitney U statistic $=-2.980, p$-value $<0.0001$ & Significant \\
5 & SSPF04 & Mann-Whitney U statistic $=-1.992, p$-value $=0.0101$ & Significant \\
6 & ESPF05 & Mann-Whitney U statistic $=-2.005, p$-value $=0.0320$ & Significant \\
7 & SSPF07 & Mann-Whitney U statistic $=-2.482, p$-value $=0.0015$ & Significant \\
8 & ETSPF07 & Mann-Whitney U statistic $=2.325, p$-value $=0.0060$ & Significant \\
9 & CCPF01 & Mann-Whitney U statistic $=-2.022, p$-value $=0.0038$ & Significant \\
10 & CCPF03 & Mann-Whitney U statistic $=-2.186, p$-value $=0.0301$ & Significant \\
11 & ETSPF02 & Mann-Whitney U statistic $=2.532, p$-value $=0.0017$ & Significant \\
12 & ESPF03 & Mann-Whitney U statistic $=2.112, p$-value $=0.0401$ & Significant \\
13 & ETSPF11 & Mann-Whitney U statistic $=2.194, p$-value $=0.0028$ & Significant \\
14 & SSPF08 & Mann-Whitney U statistic $=-2.612, p$-value $=0.0009$ & Significant \\
15 & CCPF02 & Mann-Whitney U statistic $=-2.582, p$-value $=0.0005$ & Significant \\
\hline
\end{tabular}

From the Mann-Whitney comparative analysis presented in Table 6 above, it was evident that the respondents' opinions on the factor's importance based on ethnicity (Indigenes or Foreigners) are significantly different $(p$-values $<0.05)$. As shown in the result, though the two participant groups selected the same CSPF, the order of ranking is quite different among the indigenes as compared to the foreigners.

\subsection{Factor Analysis of the 15 CSPF}

Since the same elements were selected irrespective of the participant group, a joint statistical analysis can be performed to further determine the major sustainability performance factors for increased residential satisfaction in the study area. To achieve this target, Exploratory Factor analysis (EFA) technique was employed. The choice of EFA is because the research aim is to explore and present the critical factors for increased residential satisfaction as a precursor for enhancing sustainability in the study area.

Before the factor analysis, some diagnostic tests such as Kaiser-Meyer-Olkin (KMO) measure of sampling adequacy, Bartlett's test of sphericity, and Pearson correlation were carried out to ascertain if the data series is qualified for the factor analysis. The results are presented in Table 5 below. The KMO statistic value of $65.7 \%$ shows that the sample is adequate, while Bartlett's Chi-Square estimate of 79,074 and associated probability value of $0.000<0.05$ indicate that the factor model is appropriate.

The Pearson correlation results are presented in Table 7 below: 
Table 7. Correlation Matrix.

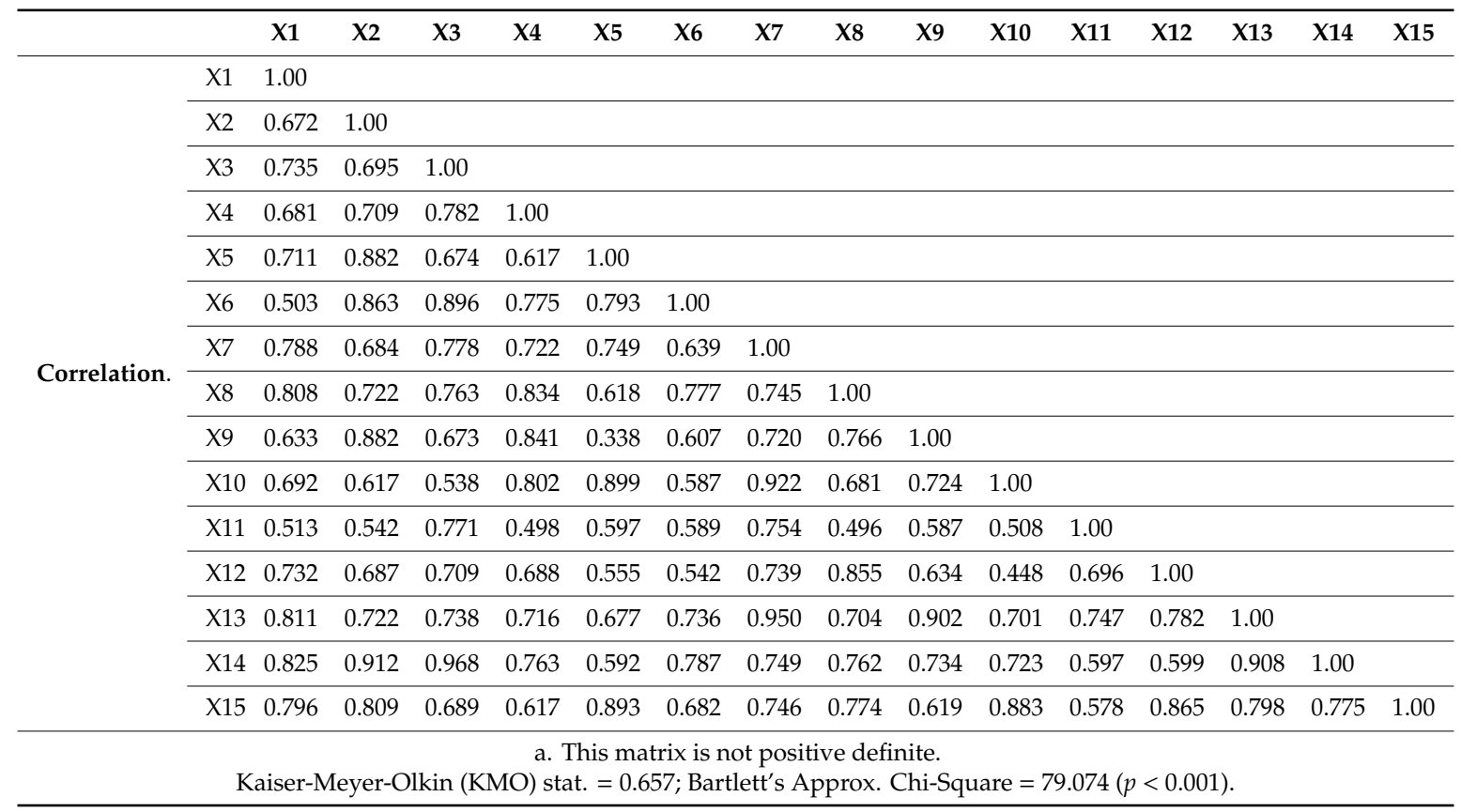

Where,

$\mathrm{X}_{1}=\mathrm{ESPF} 01=$ Cost of Housing

$\mathrm{X}_{2}=$ SSPF06 $=$ Suitable Management rules

$\mathrm{X}_{3}=$ SSPF01 $=$ Access to social infrastructure

$\mathrm{X}_{4}=\mathrm{SSPF} 04=$ Security/safety concerns

$\mathrm{X}_{5}=\mathrm{ESPF} 05=$ Cost of living within the gated community

$\mathrm{X}_{6}=$ SSPF07 $=$ Level of social mix in housing environment

$\mathrm{X}_{7}=$ ETSPF07 $=$ Reduced dependency on car within the gated community

$\mathrm{X}_{8}=\mathrm{ETSPF} 01=$ Quality of dwelling Environment

$\mathrm{X}_{9}=\mathrm{CCPF} 01=$ Architectural design of housing in relation to cultural values

$\mathrm{X}_{10}=\mathrm{CCPF03}=$ Reflection of the unique historical and cultural characteristics of the area in the design and erection of new dwellings

$\mathrm{X}_{11}=\mathrm{ETSPF} 02=$ Neighbourhood Environmental Quality

$\mathrm{X}_{12}=\mathrm{ESPF} 03=$ Tenure options

$\mathrm{X}_{13}=\mathrm{ETSPF} 11=$ Open Spaces and Green areas

$\mathrm{X}_{14}=$ SSPF08 $=$ Quality of internal spaces of housing units

$\mathrm{X}_{15}=\mathrm{CCPF} 02=$ Suitability of housing to occupants natural way of life

The Pearson correlation test matrix (which was also used in [51]) measures the partial correlation between the top 15 descriptively extracted sustainability performance factors comprising economic, social, cultural, and environmental/technological performance measures in the area. The result shows high correlation coefficients, which indicate that there are serial autocorrelation problems among the variables showing a strong significant positive correlation, while others exhibit negative correlation. This autocorrelation problem was solved using the Principal Component Analysis (PCA) technique.

To reduce the factors into a parsimonious number of a clearly defined uncorrelated matrix that can explain the variations in the observed data, the varimax rotation technique was employed. The outcome of this statistical calculation was the emergence of eight components shown in Table 8. 
Table 8. Component Scores and Communalities Matrix.

\begin{tabular}{cccccccccc}
\hline Factors & \multicolumn{9}{c}{ Component Scores } \\
\hline & $\mathbf{1}$ & $\mathbf{2}$ & $\mathbf{3}$ & $\mathbf{4}$ & $\mathbf{5}$ & $\mathbf{6}$ & $\mathbf{7}$ & $\mathbf{8}$ & Communalities \\
ESPF01 & $\mathbf{0 . 8 6 8}$ & 0.144 & 0.053 & -0.028 & -0.018 & 0.012 & -0.007 & -0.003 & 0.984 \\
SSPF06 & -0.101 & 0.057 & -0.042 & $\mathbf{0 . 5 9 2}$ & -0.071 & 0.113 & 0.023 & 0.014 & 0.898 \\
SSPF01 & 0.536 & -0.347 & 0.075 & -0.020 & -0.221 & 0.004 & -0.117 & 0.022 & 0.822 \\
SSPF04 & -0.390 & 0.102 & $\mathbf{0 . 6 0 4}$ & -0.073 & -0.203 & 0.031 & -0.026 & 0.106 & 0.865 \\
ESPF05 & 0.529 & $-\mathbf{0 . 5 0 1}$ & -0.032 & 0.301 & 0.008 & 0.233 & 0.385 & -0.007 & 0.867 \\
SSPF07 & -0.390 & 0.093 & 0.133 & -0.221 & $\mathbf{0 . 5 1 2}$ & -0.028 & 0.282 & -0.151 & 0.793 \\
ETSPF07 & -0.101 & 0.140 & -0.301 & 0.354 & 0.209 & -0.072 & 0.326 & -0.211 & 0.912 \\
ETSPF01 & 0.223 & -0.301 & 0.065 & -0.335 & 0.021 & 0.044 & -0.411 & 0.023 & 0.865 \\
CCPF01 & -0.314 & -0.225 & 0.119 & 0.430 & 0.221 & -0.023 & -0.152 & 0.046 & 0.766 \\
CCPF03 & 0.223 & 0.092 & -0.009 & -0.462 & 0.381 & -0.053 & 0.221 & 0.035 & 0.945 \\
ETSPF02 & 0.223 & -0.055 & 0.123 & -0.372 & 0.272 & -0.228 & 0.214 & -0.103 & 0.854 \\
ESPF03 & -0.466 & 0.073 & -0.206 & 0.222 & 0.045 & $\mathbf{0 . 6 2 1}$ & 0.004 & -0.005 & 0.882 \\
ETSPF11 & 0.215 & 0.146 & -0.411 & 0.261 & -0.212 & $0-.192$ & $\mathbf{0 . 6 2 2}$ & -0.011 & 0.940 \\
SSPF08 & 0.356 & 0.174 & -0.330 & -0.211 & 0.322 & -0.332 & 0.253 & -0.067 & 0.911 \\
CCPF02 & 0.226 & 0.064 & -0.012 & -0.336 & 0.337 & -0.107 & 0.201 & $\mathbf{0 . 4 4 2}$ & 906 \\
Eigenvalue & 5.16 & 3.23 & 2.53 & 1.43 & 1.12 & 1.04 & 0.98 & 0.72 & \\
Variance exp. & 28.7 & 19.5 & 17.9 & 10.3 & 9.4 & 7.2 & 4.6 & 2.1 & \\
(\%) & & & & & & & & & \\
Cumulative & 28.7 & 48.2 & 66.1 & 76.4 & 85.8 & 93.0 & 97.6 & 99.7 & \\
\%age & & & & & & & \\
\hline
\end{tabular}

Extraction Method: Principal Component Analysis. a. 8 components extracted.

From the Principal Component Analysis (PCA) result, the 15 sustainability performance factors were reduced to 8 , which collectively accounted for about $99.7 \%$ of the total variations in the area. Hence, the following factors were extracted from the respective component: Cost of Housing (ESPF01), Suitable Management rules (SSPF06), Security/safety concerns (SSPF04), Cost of living within the gated community (ESPF05), Level of social mix in housing environment (SSPF07), Tenure options (ESPF03), Open Spaces and Green areas (ETSPF11), and Suitability of housing to occupants natural way of life (CCPF02). The framework is presented in Figure 3 below was developed.

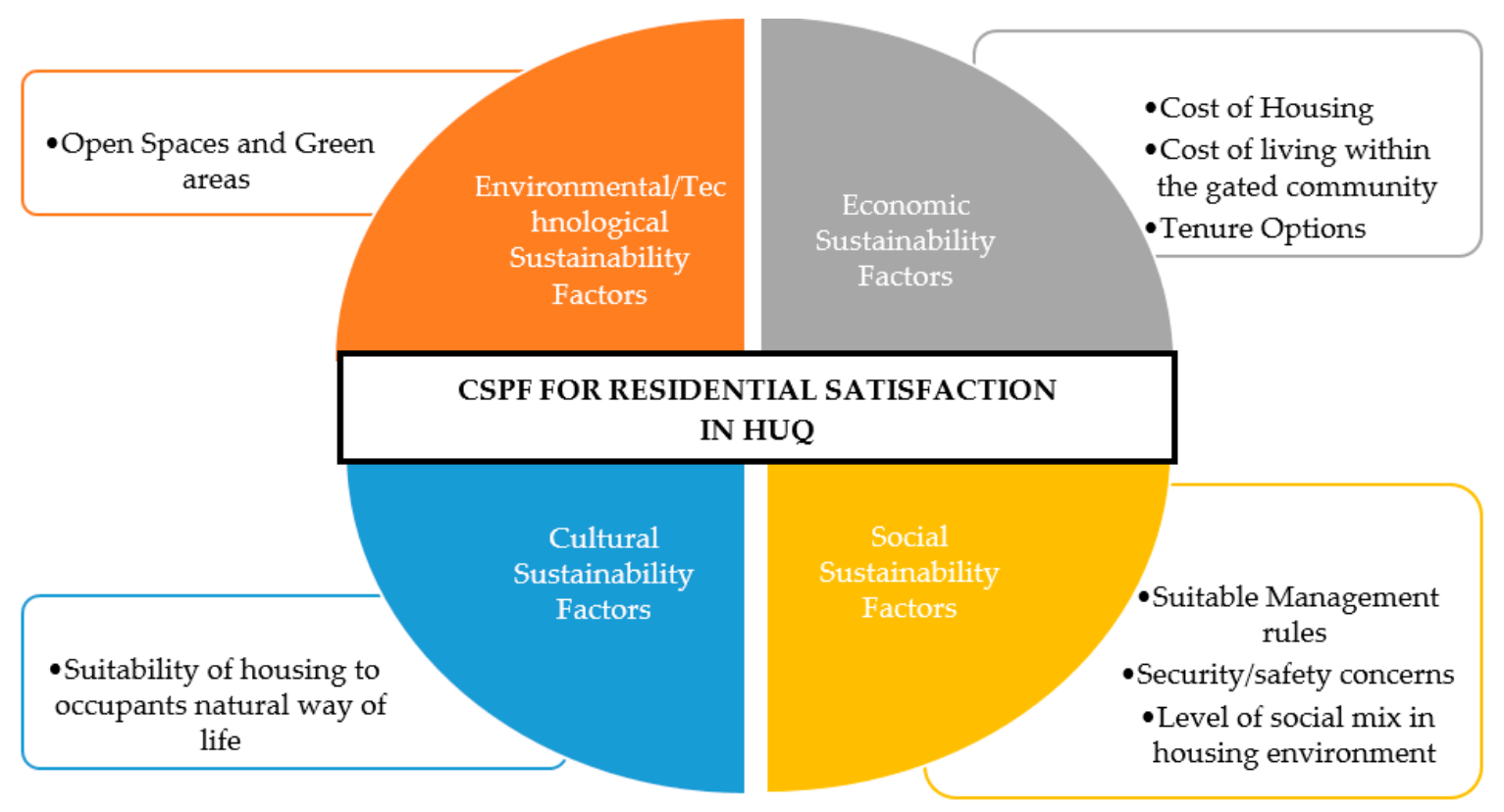

Figure 3. Framework for enhancing housing satisfaction in HUQ of the Walled City, Famagusta.

\section{Discussion}

Interventions for regeneration and sustainability attainment in HUQ have drawn the attention of several scholars (see $[2,3,14,86]$ ) who primarily focus on how experts, professionals, and government 
agencies can contribute to the urban regeneration of HUQ. However, experts, professionals and government agencies interventions for the sustainable revitalisation of HUQ alone can be inefficient and even counterproductive. As such, a vital question is, what are the other potential efficient intervention strategies? To address such a question, the perceptions of HUQ residents and those living in adjacent districts were solicited through a questionnaire survey to identify critical sustainability performance factors (CSPF) for residential satisfaction in HUQ. Relative significance analysis of the data led to the identification of 32 CSPF.

The level of residential satisfaction has served as a key criterion for evaluating residential environments (e.g., see [92]) and housing quality (e.g., see [93]). Many of these studies compare the realities of housing environment with the needs and expectations; none of these studies attempted to elicit dimensions of residential satisfaction from the perceptions of residents; they merely examine housing satisfaction in terms of factors only reviewed in the literature. To correct this anomaly, this study, through the pilot survey of the questionnaire, obtained residents' subjected opinions on other factors they consider critical.

The quantitative analysis performed in Section 4 shows the analysis of 448 questionnaires carried out with residents and non-residents of HUQ in the Walled City of Famagusta, North Cyprus. This survey enabled the authors to establish the criticality of 32 potential SPF impacting residential satisfaction in HUQ. Fifteen CSPF were established using respondents' subjective opinions. Research results showed that currently, residents of HUQ in the Walled City perceive economic factors, such as "cost of housing" and the social factor "Suitable Management rules" amongst the key significant factors influencing residential satisfaction in HUQ, ranking them first and second, respectively. This result is not surprising since housing cost or rent and its relation to income has most often been used in residential satisfaction literature to measure residential satisfaction levels amongst residents [57]. This finding is consistent with [50]'s study, which reported that higher satisfaction with housing is significantly associated with higher income while low-income levels result in decreased residential satisfaction among residents [94].

In continuation, residents considered a social factor "Suitable Management rules" as the second most critical factor impacting residential satisfaction in HUQ, even above the economic factor "Cost of living within the gated community." This finding is particularly interesting because only a few studies have recognized the impact of management rules on satisfaction levels among residents. An earlier study by [95] suggested that management policies, rules, and practices can impact satisfaction. The study by [6] demonstrated that the activities of local authorities (e.g., housing policymakers, urban planners) impact on housing satisfaction. These studies argued that by implementing effective regulations and strategies, local authorities and municipalities could practically improve the conditions that influence the satisfaction of residents. [51] reported that local authorities have a substantial role in improving residential satisfaction when they determine and implement suitable management policies. In the HUQ of the Walled City, the specific renovation rules are prepared to preserve the characteristics of historical houses/buildings and environments. These rules and policies restrict the excesses of residents in terms of housing renovations, resulting in satisfaction/dissatisfaction of residents.

Other social and qualitative factors like Access to social infrastructure (SSPF01) and Security/safety concerns (SSPF04) were ranked third and fourth, respectively. This finding negates the report of [40] who found that safety was not a concern for the majority of the residents including the old core of the city (the Walled City), and there is no problem with the social attributes. It, therefore, seems from our results that HUQ residents are beginning to recognise the importance of safety provisions and related factors in line with several scholars. For instance, [96] discovered that design principles on residential satisfaction had a significant value of 0.183 , which were mostly related to safety and security provisions. These design features according to the authors, are the safety of car parking, the lighting of public areas, the safety of indoor space, and security for children in public areas. Personal security was identified as a feature that first-time homebuyers consider when deciding on an outright purchase. The crime rate in the neighbourhood and whether a neighbourhood is gated are key factors influencing 
residential satisfaction, and the probability of homeownership among first-time homebuyers according to [77]. A safe community, as well as good leisure facilities, promote residential satisfaction [76].

Given that different interpretations have been employed in the housing satisfaction studies by researchers of diverse orientation [16], questionnaire data analyses were performed using non-parametric statistics (see $[91,97]$ ). The purpose was to establish if any significant differences exist in perceptions among residents and non-residents; first, based on the residents' ethnicity (local or foreigner), and second, according to the profile of residents/social class. Findings from the first analysis show that opinion on criteria importance differs considerably by ethnicity in Famagusta, North Cyprus. This finding is an indication that residents' opinions and perception of the factor's importance were inconsistent within the country. This perceptual irregularity is in line with the views of [96], who demonstrated that ethnicity was the moderator in relationships between neighbours regarding residential satisfaction. The authors noted that ethnic groups attempted to improve the interaction with neighbours of similar ethnicity. Furthermore, [98] pointed out families' racial/ethnic impacts their preferences for housing and neighbourhood conditions. With regard to all the practices, design principles should be consistent with the cultural context so that they could not be predefined.

The second analysis showed that the respondents' opinion does not depend on the resident profile or social class. This research, therefore, rejects the alternative hypothesis and accepts the null hypothesis for $\mathrm{H} 1$ since their $\mathrm{p}$-value is higher than 0.05 . The null hypothesis $\mathrm{H} 2$ states that residents' perceptions of the determinants of residential satisfaction in HUQ do not significantly differ based on the profile of residence/social class. However, it accepts the alternative hypothesis $\mathrm{H}_{\mathrm{A} 1}$ and rejects the null hypothesis for $\mathrm{H} 1$, which states that residents' perceptions of the determinants of residential satisfaction in HUQ do not significantly differ based on ethnicity since it has a p-value less than 0.05 .

\section{Limitations of the Study}

This study is cursory of residents' opinion, given that residential satisfaction is a dynamic process and changes over time. This article only performed a frequency analysis of the research objectives in-line with the research questions and hypotheses; it did not dive into the causes of the decline in HUQ. The study sample size is acknowledged to be relatively small. This weakness may limit the representativeness of the survey results. Consequently, the generalisation and interpretation can be improved by future research, which employs a larger sample size of respondents.

Another limitation of this study is that only the opinions of HUQ residents and residents of adjacent districts were assessed. The views of experts, academics and professionals were excluded; it would be interesting if future studies analyse residents' views on CSPF for enhanced residential satisfaction in HUQ alongside the opinions of academics, experts and professionals.

\subsection{Research Recommendations and Implications for Practice}

To the best of our knowledge, no research has been conducted on residential satisfaction in HUQ. This could be the result of few studies on HUQ. Based on the research limitations, the following is recommended for future studies: Education of the residents about the variables of residential satisfaction must be promoted so that their responses on residential satisfaction studies can provide a better understanding of their problems.

\subsection{Research Contribution to Existing Literature}

Although this research suffers some weaknesses, it makes salient contributions that are worthy of note. First, the study proposed a framework for achieving residential satisfaction in the study area through the established and validated CSPF as evaluation criteria. Secondly, the study also employed higher statistical tools. This enhanced the statistical rigour and enabled an in-depth comparison as well as the determination of statistical differences within the views of residents based on groups and social class in Famagusta, North Cyprus. Third, government agencies and international organisations can depend on the salient information in this study to allocate resources in attaining sustainable 
revitalisation of HUQ. Fourth, assessing residents views on the factors impacting residential satisfaction in HUQ revealed other important indicators that would have been ordinarily neglected by other assessment exercises such as industry professionals and stakeholders perception analysis.

Finally, utilising the established CSPF from this study, policymakers can easily evaluate the performance rate of HUQ and possible improvement policies to minimise housing abandonment and perceived dissatisfaction.

\section{Conclusions}

People's expectations of their housing and residential environment have been altered as a result of the changing life conditions occasioned by the globalization process, and HUQ are not exempted. This change has revealed that critical factors promoting residents' quality of life, as identified by residents, must be considered while specifying frameworks and models for sustainable revitalization and regeneration programs for any HUQ. Relying on a regeneration framework occasioned by professionals, governmental agencies, institutions, and experts alone will not provide the required outcome. Residents' opinion on the critical factors for residential satisfaction in HUQ for enhanced sustainability comes in handy.

Although several studies have empirically investigated the predictors of residential satisfaction in private and public urban housing, no attention has been paid to the determinants of residential satisfaction in the HUQ of cities in developing countries. Therefore, this study, by considering the specific and distinguishing characteristics of historical areas, has made a distinctive contribution to residential satisfaction literature by the inclusion of various determinants of residential satisfaction from the economic, social, cultural, and environmental dimensions, as well as employing the Relative Importance Index (RII) analytical technique for ranking the importance of the identified determinants based on residents' perception.

In as much as this study achieved its aim, it also suffers some weaknesses. The study employed a relatively small sample size of respondents. Hence, the generalisation and interpretation could be improved upon by future studies that employ a larger sample size. In light of this, the available data are not robust enough to provide a thorough cross-country view, and future studies could increase the coverage of data and corroborate the quality of the findings of this study. Subsequent studies could validate the established CSPF in this research, using evidence-based case studies.

This study has demonstrated that during the planning process of urban regeneration programs of HUQ, it is essential to consider various factors determining housing and environmental satisfaction from the prism of sustainability. In this light, user satisfaction will increase; hence, it will be possible to plan a more livable and more sustainable city life that will provide a higher level of user satisfaction. Therefore, public desire, needs, and expectations must be taken into account, and residents should be allowed to participate in the planning process of sustainable revitalisation and regeneration programs.

The findings of this study will help to better understand the residents' needs and desires in HUQ and are useful to housing policy decision-makers, urban planners, and municipalities to improve residential environments in line with the contemporary needs and expectations of residents. The results of this study also provide some insights that contribute to residential satisfaction literature as it opens a new window for further studies to test and apply the proposed framework in a case-study based survey of other historic blocks and areas. Furthermore, it can be considered a crucial step in the sustainable development process, as identifying the critical determinants of residential satisfaction helps to satisfy the contemporary needs of residents in physically degraded and urban fabric deteriorated historical environments. Although this paper provides empirical findings for modelling the predictors of residential satisfaction in the HUQ, subsequent studies should be conducted in more historic environments to provide a comprehensive picture and compare their findings with ours.

Supplementary Materials: The following are available online at http://www.mdpi.com/2071-1050/11/22/6261/s1, Sample of the questionnaires use in the research. 
Author Contributions: Conceptualization: T.D., U.D., Methodology: T.D. Supervision: U.D. Writing-Original draft: T.D., U.D.

Funding: This research received no external funding.

Acknowledgments: The authors are thankful to the various participants of the survey; their voluntary participation resulted in the success of this study. Thanks also go to the editor and anonymous reviewers whose comments and suggestions greatly improved the manuscripts' quality.

Conflicts of Interest: The authors declare no conflicts of interest.

\section{References}

1. Heath, T.; Oc, T.; Tiesdell, S. Revitalizing Historic Urban Quarters; Routledge Ltd.: London, UK, 1996. [CrossRef]

2. Doratli, N.; Hoskar, S.Ö.; Vehbi, B.O.; Fasli, M. Revitalizing a declining historic urban quarter-The walled city of Famagusta, North Cyprus. J. Arch. Plan. Res. 2007, 1, 65-88.

3. Vehbi, B.O.; Hoşkara, Ş.Ö. A Model for Measuring the Sustainability Level of Historic Urban Quarters. Eur. Plan. Stud. 2009, 17, 715-739. [CrossRef]

4. Doratli, N. Revitalizing historic urban quarters: A model for determining the most relevant strategic approach. Eur. Plan. Stud. 2005, 13, 749-772. [CrossRef]

5. Sarıoğlu Erdoğdu, G.P.; Özdemir Sari, Ö.B. Householder Satisfaction in Apartment Block Neighborhoods: Case of Ankara, Turkey. J. Urban Plan. Dev. 2017, 14, 04017022. [CrossRef]

6. Erdogan, N.; Akyol, A.; Ataman, B.; Dokmeci, V. Comparison of urban housing satisfaction in modern and traditional neighborhoods in Edirne, Turkey. Soc. Indic. Res. 2007, 81, 127-148. [CrossRef]

7. Aiello, A.; Ardone, R.G.; Scopelliti, M. Neighbourhood planning improvement: Physical attributes, cognitive and affective evaluation and activities in two neighbourhoods in Rome. Eval. Program Plan. 2010, 33, $264-275$. [CrossRef] [PubMed]

8. Boschman, S. Individual differences in the neighbourhood level determinants of residential satisfaction. Hous. Stud. 2018, 33, 1-17. [CrossRef]

9. O'Ibem, E.; Opoko, A.P.; Aduwo, E.B.; O Ibem, A.P.O.E. Exploring the impact of urban neighbourhood environment on satisfaction with life in public housing in Nigeria. Urban Des. Int. 2016, 21, 317-331. [CrossRef]

10. Etminani-Ghasrodashti, R.; Majedi, H.; Paydar, M. Assessment of Residential Satisfaction in Mehr Housing Scheme: A Case Study of Sadra New Town, Iran. Hous. Theory Soc. 2017, 2, 1-20. [CrossRef]

11. Ghafourian, M.; Hesari, E. Evaluating the Model of Causal Relations Between Sense of Place and Residential Satisfaction in Iranian Public Housing (The Case of Mehr Housing in Pardis, Tehran). Soc. Indic. Res. 2017, 139, 695-721. [CrossRef]

12. Salleh, A.G. Neighbourhood factors in private low-cost housing in Malaysia. Habitat Int. 2008, 32, $485-493$. [CrossRef]

13. Doratli, N. A Model for Conservation and Revitalization of Historic Urban Quarters in Northern Cyprus. Ph.D. Thesis, Eastern Mediterranean University, Gazimagusa, Turkey, 2000.

14. Tanrikul, A.; Hoşkara, Ş. A New Framework for the Regeneration Process of Mediterranean Historic City Centres. Sustainability 2019, 11, 4483. [CrossRef]

15. WHITRAP. City and Society: Community, Space, and Governance. In Proceedings of the Annual Conference ofWorld Heritage Institute of Training and Research for the Asia and the Pacific Regional under the Eauspices of UNESCO, Shanghai, China, 10-11 April 2015.

16. Onibokun, A.G. Evaluating Consumers' Satisfaction with Housing: An Application of a Systems Approach. J. Am. Inst. Plan. 1974, 40, 189-200. [CrossRef]

17. Canter, D.; Rees, K. A multivariate model of housing satisfaction. Appl. Psychol. 1982, 31, 185-207. [CrossRef]

18. Levy-Leboyer, C.; Ratiu, E. The need for space and residential satisfaction. Archit. Comport. Archit. Behav. 1993, 9, 475-490.

19. Hur, M.; Morrow-Jones, H. Factors That Influence Residents' Satisfaction With Neighborhoods. Environ. Behav. 2008, 40, 619-635. [CrossRef]

20. Ogu, V.I. Urban Residential Satisfaction and the Planning Implications in a Developing World Context: The Example of Benin City, Nigeria. Int. Plan. Stud. 2002, 7, 37-53. [CrossRef] 
21. Beveridge, A.A.; Campbell, A.; Converse, P.E.; Rodgers, W.L. The Quality of American Life: Perceptions, Evaluations, and Satisfactions. Politi-Sci. Q. 1976, 91, 529. [CrossRef]

22. Mohit, M.A.; Raja, A.M.M.A.-K. Residential satisfaction-concept, theories and empirical studies. Plan. Malays. J. 2014, 12, 47-66. [CrossRef]

23. Rosenberg, M.J.; Hovland, C.I.; McGuire, W.J.; Abelson, R.P.; Brehm, J.W. Attitude Organization and Change: An Analysis of Consistency among Attitude Components; (Yales Studies in Attitude and Communication); Yale Univer. Press: Oxford, UK, 1960; Volume III.

24. Amérigo, M.; Aragonés, J.I. Residential satisfaction in council housing. J. Environ. Psychol. 1990, 10, 313-325. [CrossRef]

25. Weidemann, S.; Anderson, J.R.; Butterfield, D.I.; O'Donnell, P.M. Residents' perceptions of satisfaction and safety: A basis for change in multifamily housing. Environ. Behav. 1982, 14, 695-724. [CrossRef]

26. Gold, J.R. An Introduction to Behavioral Geography; University Press: Oxford, UK, 1980.

27. Marans, R.W.; Rodgers, W. Toward Understanding of Community Satisfaction; Metropoliten America in Contemporary Perspectives içinde; Vincent, P., Ed.; Halstedd Press: New York, NY, USA, 1975; pp. $299-352$.

28. Wiesenfeld, E. Public housing evaluation in venezuela: A case study. J. Environ. Psychol. 1992, 12, $213-223$. [CrossRef]

29. Morrissy, E.; Handal, P.J. Characteristics of the residential environment scale: Reliability and differential relationship to neighborhood satisfaction in divergent neighborhoods. J. Community Psychol. 1981, 9, 125-132. [CrossRef]

30. Bardo, J.W.; Hughey, J.B. The Structure of Community Satisfaction in a British and an American Community. J. Soc. Psychol. 1984, 124, 151-157. [CrossRef]

31. Berköz, L.; Turk, S..Ş.; Kellekci, Ö.L. Environmental Quality and User Satisfaction in Mass Housing Areas: The Case of Istanbul. Eur. Plan. Stud. 2009, 17, 161-174. [CrossRef]

32. Lepkova, N.; Butkiene, E.; Bełej, M. Study of Customer Satisfaction with Living Conditions in New Apartment Buildings. Real Estate Manag. Valuat. 2016, 24, 52-70. [CrossRef]

33. Brackertz, N.; Kenley, R. Evaluating community facilities in local government: Managing for service enablement. J. Facil. Manag. 2002, 1, 283-299. [CrossRef]

34. Gruber, K.J.; Shelton, G.G. Assessment of neighborhood satisfaction by residents of three housing types. Soc. Indic. Res. 1987, 19, 303-315. [CrossRef]

35. Mohamed, A.A.A.; Gammaz, S.A. Assessment of the Role of International Organizations in the Rehabilitation of Historic Districts: Case of Darb Alahmar. J. Urban Plan. Dev. 2012, 138, 215-226. [CrossRef]

36. Fang, Y. Residential Satisfaction, Moving Intention and Moving Behaviours: A Study of Redeveloped Neighbourhoods in Inner-City Beijing. Hous. Stud. 2006, 21, 671-694. [CrossRef]

37. Galster, G.C. Evaluating indicators for housing policy: Residential satisfaction vs marginal improvement priorities. Soc. Indic. Res. 1985, 16, 415-448. [CrossRef]

38. Furbey, R.; Goodchild, B. Method and methodology in housing user research. Hous. Stud. 1986, 1, $166-181$. [CrossRef]

39. Jiang, W.; Feng, T.; Timmermans, H.; Li, H. A gap-theoretical path model of residential satisfaction and intention to move house applied to renovated historical blocks in two Chinese cities. Cities 2017, 71, 19-29. [CrossRef]

40. Oktay, D.; Rustemli, A. Measuring the quality of urban life and neighbourhood satisfaction: Findings from Gazimagusa (Famagusta) area study. Int. J. Soc. Sci. Humanity Studies 2010, 2, 27-37.

41. Van Kamp, I.; Leidelmeijer, K.; Marsman, G.; De Hollander, A. Urban environmental quality and human well-being: Towards a conceptual framework and demarcation of concepts; a literature study. Landsc. Urban Plan. 2003, 65, 5-18. [CrossRef]

42. Burby, R.J.; Rohe, W.M. Providing for the Housing Needs of the Elderly. J. Am. Plan. Assoc. 1990, 56, 324-340. [CrossRef]

43. Boyle, M.; Kiel, K. A survey of house price hedonic studies of the impact of environmental externalities. J. Real Estate Lit. 2001, 9, 117-144. [CrossRef]

44. Varady, D.P.; Carrozza, M.A. Toward a Better Way to Measure Customer Satisfaction Levels in Public Housing: A Report from Cincinnati. Hous. Stud. 2000, 15, 797-825. [CrossRef]

45. Parkes, A.; Kearns, A.; Atkinson, R. What Makes People Dissatisfied with their Neighbourhoods? Urban Stud. 2002, 39, 2413-2438. [CrossRef] 
46. Kellekci, Ö.L.; Berköz, L. Mass Housing: User Satisfaction in Housing and its Environment in Istanbul, Turkey. Eur. J. Hous. Policy 2006, 6, 77-99. [CrossRef]

47. Türkoğlu, H. Residents' satisfaction of housing environments: The case of Istanbul, Turkey. Landsc. Urban Plan. 1997, 39, 55-67. [CrossRef]

48. Lu, M. Determinants of Residential Satisfaction: Ordered Logit vs. Regression Models. Growth Chang. 1999, 30, 264-287. [CrossRef]

49. Galster, G.C.; Hesser, G.W. Residential satisfaction: Compositional and contextual correlates. Environ. Behav. 1981, 13, 735-758. [CrossRef]

50. Zanuzdana, A.; Khan, M.; Kraemer, A. Housing satisfaction related to health and importance of services in urban slums: Evidence from Dhaka, Bangladesh. Soc. Indic. Res. 2013, 112, 163-185. [CrossRef]

51. Mohit, M.A.; Ibrahim, M.; Rashid, Y.R. Assessment of residential satisfaction in newly designed public low-cost housing in Kuala Lumpur, Malaysia. Habitat Int. 2010, 34, 18-27. [CrossRef]

52. Cho, S.H.; Lee, T.K. A study on building sustainable communities in high-rise and high-density apartments-Focused on living program. Build. Environ. 2011, 46, 1428-1435. [CrossRef]

53. Addo, I.A. Assessing residential satisfaction among low income households in multi-habited dwellings in selected low income communities in Accra. Urban Stud. 2016, 53, 631-650. [CrossRef]

54. Kasarda, J.D.; Janowitz, M. Community Attachment in Mass Society. Am. Sociol. Rev. 1974, $39,328$. [CrossRef]

55. Caldieron, J. Residential satisfaction in La Perla informal neighborhood, San Juan, Puerto Rico. Oida Int. J. Sustain. Dev. 2011, 2, 77-84.

56. Hourihan, K. Context-dependent models of residential satisfaction: An analysis of housing groups in Cork, Ireland. Environ. Behav. 1984, 16, 369-393. [CrossRef]

57. Baiden, P.; Arku, G.; Luginaah, I.; Asiedu, A.B. An assessment of residents' housing satisfaction and coping in Accra, Ghana. J. Public Health 2011, 19, 29-37. [CrossRef]

58. Mustapha, F.; Al-Abed, A.; Wild, S. A model for assessing the effectiveness of public housing in Sana'a (Republic of Yemen). Constr. Manag. Econ. 1995, 13, 457-465. [CrossRef]

59. Sinai, I. Moving or Improving: Housing Adjustment Choice in Kumasi, Ghana. Hous. Stud. 2001, 16, 97-114. [CrossRef]

60. Konadu-Agyemang, K. A survey of housing conditions and characteristics in Accra, an African city. Habitat Int. 2001, 25, 15-34. [CrossRef]

61. Ukoha, O.M.; Beamish, J.O. Assessment of residents' satisfaction with public housing in Abuja, Nigeria. Habitat Int. 1997, 21, 445-460. [CrossRef]

62. Satsangi, M.; Kearns, A. The Use and Interpretation of Tenant Satisfaction Surveys in British Social Housing. Environ. Plan. C Gov. Policy 1992, 10, 317-331. [CrossRef]

63. Kahraman, Z.E.H. Dimensions of housing satisfaction: A case study based on perceptions of rural migrants living in Dikmen. METU JFA 2013, 1, 1-27.

64. Dahmann, D.C. Assessments of Neighborhood Quality in Metropolitan America. Urban Aff. Q. 1985, 20, 511-535. [CrossRef]

65. Varady, D.P. Determinants of Residential Mobility Decisions The Role of Government Services in Relation to Other Factors. J. Am. Plan. Assoc. 1983, 49, 184-199. [CrossRef]

66. Amole, D. Residential satisfaction in students' housing. J. Environ. Psychol. 2009, 29, 76-85. [CrossRef]

67. Thaman, K.H. Shifting sights: The cultural challenge of sustainability. High. Educ. Policy 2002, 15, $133-142$. [CrossRef]

68. Makinde, O.O. Influences of socio-cultural experiences on residents' satisfaction in Ikorodu low-cost housing estate, Lagos state. Environ. Dev. Sustain. 2015, 17, 173-198. [CrossRef]

69. Munro, D.A. Sustainability: Rhetoric or reality? In A Sustainable World: Defining and Measuring Sustainable Development, Published for IUCN-the World Conservation Union by the International Center for the Environment and Public Policy; Trzyna, T.C., Osborn, J.K., Eds.; California Institute of Public Affairs: Sacramento, CA, USA, 1995; pp. 27-35.

70. Bonaiuto, M.; Fornara, F.; Alves, S.; Ferreira, I.; Mao, Y.; Moffat, E.; Piccinin, G.; Rahimi, L. Urban environment and well-being: Cross-cultural studies on Perceived Residential Environment Quality Indicators (PREQIs). Cogn. Process. 2015, 16, 165-169. [CrossRef] [PubMed] 
71. Jiboye, A.D. A Study of Public Housing Satisfaction in Lagos, Nigeria. Ph.D. Thesis, Department Urban Regional Planning, Obafemi Awolowo University, Ile-Ife, Nigeria, 2008.

72. Lin, S.; Li, Z. Residential satisfaction of migrants in Wenzhou, an 'ordinary city' of China. Habitat Int. 2017, 66, 76-85. [CrossRef]

73. Tan, T.H. Residential satisfaction in gated communities: Case study of desa park city, Kuala Lumpur, Malaysia. Prop. Manag. 2016, 34, 84-99. [CrossRef]

74. Hudson, W.R.; Haas, R.; Udding, W. Infrastructure Management: Integrating Design, Construction, Maintenance, Rehabilitation, and Renovation; McGraw-Hill: New York, NY, USA, 1997.

75. Ibem, E.O.; Aduwo, E.B. Assessment of residential satisfaction in public housing in Ogun State, Nigeria. Habitat Int. 2013, 40, 163-175. [CrossRef]

76. Ren, H.; Folmer, H. Determinants of residential satisfaction in urban China: A multi-group structural equation analysis. Urban Stud. 2017, 54, 1407-1425. [CrossRef]

77. Teck-Hong, T. Housing satisfaction in medium- and high-cost housing: The case of Greater Kuala Lumpur, Malaysia. Habitat Int. 2012, 36, 108-116. [CrossRef]

78. Jorgensen, A.; Hitchmough, J.; Dunnett, N. Woodland as a setting for housing-appreciation and fear and the contribution to residential satisfaction and place identity in Warrington New Town, UK. Landsc. Urban Plan. 2007, 79, 273-287. [CrossRef]

79. Riza, M.; Doratli, N. The critical lacuna between new contextually juxtaposed and freestyle buildings in historic settings. J. Archit. Plan. Res. 2015, 3, 234-257.

80. Oktay, D.; Rüstemli, A.; Marans, R.W. Determinants of neighborhood satisfaction among local residents and international students: a case study in Famagusta, North Cyprus. J. Archit. Plan. Res. 2012, 29, $224-240$.

81. Liu, L.; Jensen, M.B. Green infrastructure for sustainable urban water management: Practices of five forerunner cities. Cities 2018, 74, 126-133. [CrossRef]

82. Maliene, V.; Malys, N. High-quality housing-A key issue in delivering sustainable communities. Build. Environ. 2009, 44, 426-430. [CrossRef]

83. Rustem, K. North Cyprus Almanac; Contact Type Setting Systems Ltd.: London, UK, 1987.

84. Oktay, D.; Rüstemli, A.; Marans, R.W. Neighborhood satisfaction, sense of community, and attachment: Initial findings from Famagusta quality of urban life study. Itu A/Z J. 2009, 6, 6-20.

85. Mason, R.; Fund, W.M.; Tumer, E.U.; Ünlü, A.K.; Silman, R.; Schmid, W. The Walled City of Famagusta: A Compendium of Preservation Studies, 2008-2012; World Monuments Fund: New York, NY, USA, 2012.

86. Doratli, N.; Hoşkara, Ş.Ö.; Fasli, M. An analytical methodology for revitalization strategies in historic urban quarters: A case study of the Walled City of Nicosia, North Cyprus. Cities 2004, 21, 329-348. [CrossRef]

87. Hoşkara, S.Ö.; Çavuşoğlu, B.T.; Öngül, Z. Legal Frameworks And Housing Environments in North Cyprus. Metu J. Fac. Archit. 2009, 26, 81-100.

88. Dincyurek, O.; Turker, O.O. Learning from traditional built environment of Cyprus: Re-interpretation of the contextual values. Build. Environ. 2007, 42, 3384-3392. [CrossRef]

89. Sekaran, U.; Bougie, R. Research Methods for Business: A Skill Building Approach, 5th ed.; John Wiley and Sons: Hoboken, NJ, USA, 2010.

90. Morenikeji, W. Research and Analytical Methods for Social Scientists, Planners and Environmentalists; Jos University Press Limited: Jos, Nigeria, 2006; Volume 102, pp. 180-182.

91. Mulliner, E.; Maliene, V. An analysis of professional perceptions of criteria contributing to sustainable housing affordability. Sustainability 2015, 7, 248-270. [CrossRef]

92. Anderson, J.R.; Weidemann, S. Developing and Utilizing Models of Resident Satisfaction. In Toward the Integration of Theory, Methods, Research, and Utilization; Springer Science and Business Media LLC: Berlin, Germany, 1997; pp. 287-314.

93. Altas, N.E.; Ozsoy, A. Spatial adaptability and flexibility as parameters of user satisfaction for quality housing. Build. Environ. 1998, 33, 315-323. [CrossRef]

94. Fallahi, B.; Mehrad, A. The effect of income on job satisfaction and residential satisfaction: A literature review. J. Educ. Health Community Psychol. 2015, 4, 55-60.

95. Francescato, G.; Weidemann, S.; Anderson, J.R. Evaluating the Built Environment from the Users' Point of View: An Attitudinal Model of Residential Satisfaction. In Building Evaluation; Springer Science and Business Media LLC: Berlin, Germany, 1989; pp. 181-198. [CrossRef] 
96. Riazi, M.; Emami, A. Residential satisfaction in affordable housing: A mixed method study. Cities 2018, 82, 1-9. [CrossRef]

97. Ezennia, I.S.; Hoskara, S.O. Exploring the Severity of Factors Influencing Sustainable Affordable Housing Choice: Evidence from Abuja, Nigeria. Sustainability 2019, 11, 5792. [CrossRef]

98. Shuey, E.A.; Leventhal, T.; Coley, R.L. Housing characteristics over time: Identifying patterns for low-income families. J. Poverty 2016, 20, 102-125. [CrossRef]

(C) 2019 by the authors. Licensee MDPI, Basel, Switzerland. This article is an open access article distributed under the terms and conditions of the Creative Commons Attribution (CC BY) license (http://creativecommons.org/licenses/by/4.0/). 